\title{
The In-deep Study Problems Organizers Inclusive Education of Medium School in Learning Science in Padang
}

\author{
Festiyed, Mega Iswari \\ Universitas Negeri Padang, Indonesia \\ E-mail: Festiyed@fmipa.unp.ac.id
}

\begin{abstract}
This study aims to identify where the occurrence of bottlenecks in the science learning process of secondary school inclusive education providers for children with special needs (ABK), through deep study. Informants in this research are teachers who are involved in science learning in schools implementing inclusive education in Padang city. Data were collected by interview, observation and questionnaire method as the main method. Assistive methods in the form of documentation. Qualitative data analysis through 4 paths is data collection, data reduction, data display, draw a conclusion. The result of initial research of 102 schools SMA / MA / SMK in Padang city there are problems of interaction of six components of education process (curriculum, educator, learner, facilities and infrastructure, technology and learning media, assessment system). From 102 schools and there are 4 schools conducting inclusive education with 56 students spread in SMK Negeri 4 as many as 18 people, SMK Negeri 6 as many as 27 people, SMK Negeri 7 as many as 8 people, SMK Negeri 8 as many as 3 people. based on the problem which related to teachers, students, schools, communities, and government experienced problems in the implementation of inclusive education because ABK difficulty varies according to their needs. Science learning for $\mathrm{ABK}$ has not done well according to the needs, characteristics, and limits of ability possessed by children with special needs. The guidance model, not yet focused on non-adaptive behavior or deviant behavior before they conduct activities of individual learning activities program.
\end{abstract}

Keywords: deep study, learning science, children with special needs, inclusive education

\section{INTRODUCTION}

Education is a place for every individual in the learning process, to develop knowledge, skills and attitudes and all the potential that is in him. In the explanation of the Law of RI, number 20 of 2003 on Sisdiknas can be understood that every child is entitled to increase all the potential that exists in him through education. But not all children are born in normal and perfect condition. Not a few of us encounter children born with less normal conditions, who have a disruption to their physical and mental development. Children with Special Needs (ABK) is another term to replace the word "Extraordinary Child" (ALB) which indicates a special abnormality. Children with special needs have different characteristics between one and the other. Children with Special Needs are; Children with visual impairment (blind), Children with hearing and speech impairment, children with the impaired developmental ability (tunagrahita), children with physical or motor disturbances (tunadaksa), Children with maladjustment behavior disorder, Children with autism disorder (autism children), children with the hyperactive disorder (attention deficit disorder with hyperactive), children with learning disabilities (learning disability or specific learning disability).
Children with multiple development disorders (multihandicapped and developmentally disabled children).

Inclusive Education puts children with special needs to learn together with normal children in one class in public schools. Mikail (2012), the provision of education in which children who have abnormalities (mild, moderate, or severe) and normal children can learn together in public schools. Inclusive education is a model of current educational for children with special needs who formally raised in the statement in Salamanca June 1994 at the world conference to discuss about education for children Berke heal \& condition particular, which has a fundamental principle of education inclusive is for enabling all children with special needs should learn together regardless of the difficulties or differences that exist in them. The opinion of Susan Stainback \& William Stainback (1992) states that an inclusive school is a school that caters to all children with special needs students in the same class.

A special needs child requires a pattern of its own according to their needs, which differ from one to another. In the preparation of learning programs for each field of study, class teachers should have personal data of each student. Personal data that is related to the specific characteristics, abilities and 
weaknesses, competencies, and level of development. Characteristics of specific children with special needs in general related to the level of functional development. Specific characteristics include the level of motor sensory development, cognitive, language skills, selfskills, self-concept, social interaction ability, and creativity (Tarnoto, 2016).

To know clearly about the characteristics of each student, the teacher first performs a screening or assessment to know clearly about the competence of the students themselves concerned. The goal is that when programming the learning, have been thinking about: Learning interventions are considered appropriate. Assessment here is an activity to determine the ability and weakness of each learner in terms of cognitive development and social development, sensitive observation. These activities usually require special specialists on a standard or self-made basis by classroom teachers. Teachers who inhabit are teachers who are able to organize teaching activities in the classroom through individual learning programs with the training ability and weakness of each individual student. Where during the process of activities, classroom teachers are challenged to be able to provide specific interventions to overcome the form of behavioral abnormalities that arise, so that learning goes smoothly.

The existence of different characteristics of each learner with special needs will require special skills of teachers. Teachers are required to have the ability to connect by combining the abilities and talents of each child in several aspects (Giangreco, 2013). These aspects include the ability to think, see, hear, speak, and socialized way. These things are directed at the success of the ultimate goal of learning, namely changes in behavior toward maturity. The ability of the teacher is a teacher's aptitude in aligning its existence with the existing curriculum and then mixing it into an individual learning program. Learning model of students with special needs prepared by teachers in school, shown so that learners are able to interact with the social environment. The specially arranged learning through self-learners excavation capabilities of the most dominant and based on the applicable curriculum.

Guidance models for learners with special needs should be focused on non-adaptive behaviors or deviant behavior before they engage in individual learning activities. Such guidance can be applied in environmental conditioning that can achieve optimal development in the development of behaviors in accordance with the tasks, development tasks. Psychosocial behavior problems that often arise are 1. Fear as in the fear of animals, dark, and others. 2. Aggressive behavior, which appears on the actions of children who tend to hurt other children. 3. Silence, withdrawal and/or low self-esteem. Or often also the term children with the autism culture.
Based on the description data required teachers and other parties associated with the learning process and education of children with special needs to see an interaction of six components of the educational process (curriculum, educators, learners, facilities and infrastructure, technology and learning media, assessment system ), so a teacher will be able to develop an educational program $\mathrm{n}$ in accordance with the needs, characteristics, and limit the ability of children in need special. The existence of different characteristics of each learner with special needs will require special skills of teachers. Teachers are required to have the ability to connect by combining the abilities and talents of each child in several aspects. These aspects include the ability to think, see, hear, speak, and socialized way. These things are directed at the success of the ultimate goal of learning, namely changes in behavior toward maturity.

This study aims to identify where the occurrence of bottlenecks in the process of learning science in secondary schools of inclusive education providers for children with special needs (student needs special needs), through index study. Learning Science is very close to the surrounding natural phenomena so that science education must be packaged in the form of integration or integrated. This will train learners to get used to thinking holistically by looking at all the issues and not just thinking fragmented (Festiyed, 2015). This holistic thinking is also one of the characters that every individual need in solving all problems in life.

\section{METHOD}

Learn and collect data comprehensively, new and actual from an interaction of six component of education process (curriculum, educator, learner, facility and infrastructure, technology and learning media, assessment system ) for secondary education, then do verification and validation of data for identify where bottlenecks occur in the learning process for inclusive education providers, through in deep study - Data were collected by interview, observation and questionnaire method as the main method Carrington \& Robinson (2004). Assistive methods in the form of documentation. Qualitative data analysis through 4 paths is data collection, data reduction, data display, draw a conclusion. For the academic year 2016/2017 from 102 high school / MA / SMK schools in Padang there are 4 schools conducting inclusive education with 56 students spread in SMK Negeri 4 as many as 18 people, SMK Negeri 6 as many as 27 people, SMK Negeri 7 as many as 8 people, SMK Negeri 8 for 3 people. As Informants in this study are teachers who are involved in science learning for 56 people crew. 


\section{FINDINGS AND DISCUSSION}

\section{Findings}

School Problem Analysis Results based on previous research for the interaction of six components of the educational process (curriculum, educators, learners, facilities and infrastructure, technology and learning media, assessment system ) for secondary education, in Padang. Qualitatively problems encountered in the implementation of the curriculum in 2013 due to several factors as follows: 1. The difficulty of changing the mindset of teachers, 2.Perubahan learning process from teacher centered to student centered, 3.rendahnya moral, spiritual, cultural reading and researching. 4. Lack of mastery of IT by Teacher 5. weakness of administrative dominance, 6 . teacher tendency that emphasizes more cognitive aspects. In fact, teachers should also provide the same portion of effective and psychomotor aspects. 7. there are still many teachers who do not want to become learners. In fact, 8 . a teacher is required to continue to increase knowledge and expand his horizons, especially after the enactment of the 2013 curriculum. In essence, this 2013 curriculum requires teachers more creative and innovative in the process of teaching, as usual, new things will get rejected because it is comfortable with the learning process which has been done before, in addition, there are still many schools that not yet using the 2013 curriculum on the grounds still notable, especially schools located in the area.

Based on the qualitative review of previous research (Festiyed, 2015), of 102 schools SMA / MA / SMK in the data obtained teacher education level almost all schools have a minimum of a diploma qualified high school teacher (the game no.41, 2007), approximately $94 \%$ have a diploma S1, S2, and S3. Only about $6 \%$ are not yet qualified or still have a D3 diploma. Judging from the distribution of diplomas by type of school, it is assumed that MA and private SMK schools do not have teachers with S2 and S3 degree, consequently will have difficulty developing. While the distribution of teacher certificates according to rural and urban locations is relatively close to the same.

The suitability of the lessons learned by the teacher is about $74 \%$ in accordance with his last education and there are still $5 \%$ that are not in accordance with his last education. This shows the role of headmaster and education officials in appointment and placement does not take into account the needs of teachers with existing lessons. Teacher empowerment has not been fully implemented by the local government (local government). For example, local governments have not conducted an evaluation of education, including teacher evaluation. This is often the case, so the application of K13 can be slowed down.
The suitability of the lessons learned by the teacher is about $74 \%$ in accordance with his last education and there are still $5 \%$ that are not in accordance with his last education. This shows the role of headmaster and education officials in appointment and placement does not take into account the needs of teachers with existing lessons. Teacher empowerment has not been fully implemented by local government (local government). For example, local governments have not conducted an evaluation of education, including teacher evaluation. This is often the case, so the application of K13 can be slowed down.

Implementation of $\mathrm{K} 13$ actually requires the creation of an educational climate that enables the growth of intellectual and scientific spirit for every teacher, starting from home, at school, or in society. In developing the intellectual spirit of the teacher one of them can be through participation in the seminar. In relation to seminars related to the research of MA, SMK, and SMA teachers about $12 \%$ each year have followed and $31 \%$ have not at all attended the seminar. Teachers from rural areas followed more (16\%) than urban areas (13\%) and public schools (19\%) than private $(9 \%)$. Further seminars related to the latest learning and education $15 \%$ have followed and $12 \%$ have not followed. Among those who attended high school teachers from rural areas followed more $(9 \%)$ than urban areas $(6 \%)$. Private schools are more rural (11\%) than private $5 \%$. This shows that private schools are not yet optimum for improving their learning field.

A good learning process should bring students into the real world (CTL). This research asks the question of how percent of teachers bring practicum students to labor and to the field. The findings of this study of approximately $19 \%$ of teachers have brought students to labor as much as 6 times for one semester, while $47 \%$ of teachers have not brought students to the laboratory for practicum. About $4 \%$ of teachers have taken students to the field for practicum more than 6 times for one semester, and only $55 \%$ have not brought students to the field. In Table 21, approximately $47 \%$ of students from rural groups admitted to taking a computer practice more than 6 times for one semester, and only $64 \%$ of urban students admitted to taking a computer practice more than 6 times per semester. Practical computer activity has been performed more than 6 times in a semester in public high school and vocational school about $20 \%$, but for MA that comes from rural only 1 to 2 times only. So is the private rural MA school does not bring students practicum computers?

The association of the teacher's diploma with the seminar and activity activities to bring the students to the laboratory and fieldwork can be seen in Figure 1. 
Figure 1. Graph of teacher's diploma with seminar activity and laboratory activities

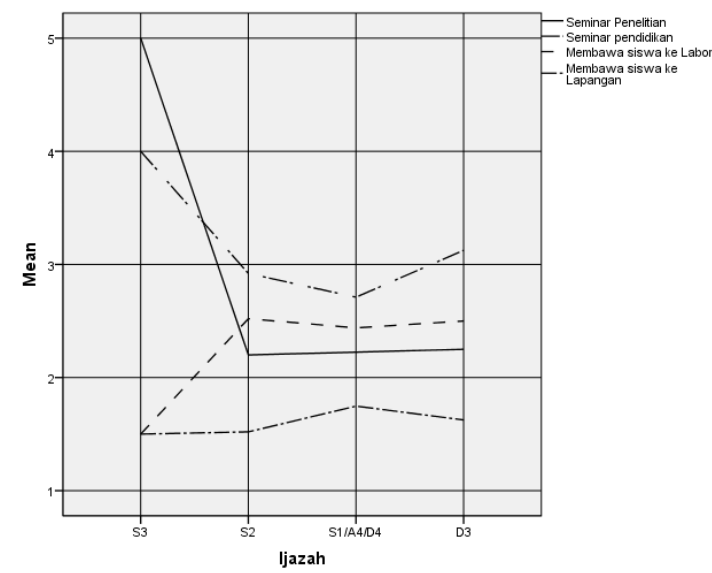

Figure 2. Perceptions of teachers and students' perceptions of their teachers

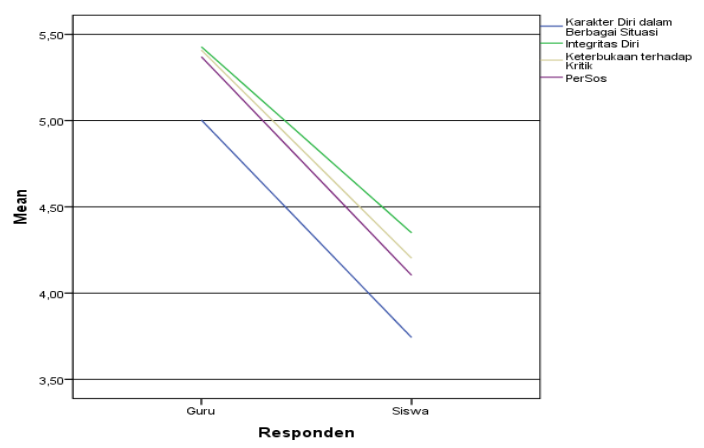

This section contains the results of research findings obtained from research data and associated with the hypothesis.

Please check all the pictures in your journal, either on the screen, as well as the results of the print version. When checking the print version of the image, make sure that: (1) the colors have sufficient contrast, (2) the picture is quite clear, (3) all of the labels in the image can be read. Pictures are numbered using Arabic numerals. Captions should be in regular font size 9 pt.

Captions in a row (for example, Figure 2) is placed on the left (left), whereas multi-line captions must be aggregated left. A caption with the image numbers should be placed after related images.

In harmony with that, the teacher failed to take the initiative to use Alam Takambang Jadi Guru, to bring children to the field, especially schools located in rural areas. Field observations found that most high school, MA and SMK schools have not been equipped with adequate laboratory facilities.

From the above findings, it can be concluded that the attention of Cadres and Headmaster assume that the labor requirement is not critical compared to the achievement of the UN and the number of students who graduated. additionally the lack of teacher initiative to utilize nature as an open laboratory. And not yet oriented to the quality of the learning process and to teach the student. There is an opinion saying that if the UN is good then it means that children have learned well and teachers have been teaching well too. This view seems to be wrong because it simplifies a complex problem too much. Should be in the development of education identified components of education that have not developed. If these weak components can be developed, then the development can occur significantly. Then the curriculum needs to be integrated into a systematic and integrative so that no one part of the indicator is forgotten.

In the form of tasks assigned by teachers mostly in the form of written responses, discussions and presentations of $75 \%, 89 \%$, and $68 \%$ respectively for both public and private schools coming from rural or urban groups. This shows that the mastery of teaching instruction evaluation is still inadequate.

Learning tools have been used by teachers in the form of RP 96\%, LKS 70\%, Material Summary 78\%, $57 \%$ module, $73 \%$ textbook, $63 \%$ package book, but LDS only $24 \%$ When compared to the task used, requires LDS. This data reinforces the conclusion that teachers' understanding of teaching tasks is still highly mechanistic.

From the facts mentioned above, although the certificate of a teacher has met the requirements and the distribution of teachers between urban and rural is relatively proportional, but this study proves that mastery of evaluation and teaching methods is not adequate. This is probably because the teacher is so confident that he no longer need to develop his own potential. In the case when viewed from the students' perception it is contradictory, as can be seen in Figure 2.

Figure 2 shows self-character, self-integrity, openness to criticism, the teacher's social role seen from teacher perception and student perception. From the graph, it is seen that for all components of the teacher tends to rate himself too high, while students judge otherwise.

Factors of the learning environment situation also play a role in learning such as lighting and noise of the school environment. When compared with the standard in our country about the artificial lighting for the class that is 200 - 300 lux. (Artificial Lighting Standards in the Building, 1978), and for noise on zona B (Intensity 45-55 dB, Zone dedicated to housing, Education, and recreation ). Then the light intensity in the class and the library meets the standard, but the laboratory has not met. For the sound intensity in all rooms is above 55 $\mathrm{dB}$, so above the noise standard. 


\section{Figure 3. Percentage Ten Categories of Problems Related Teachers}

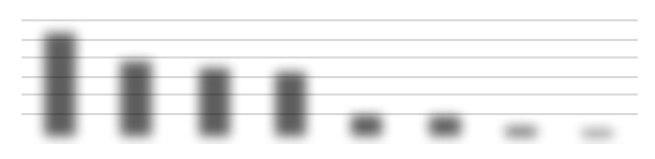

Perhaps this is also the difficulty of students who concentrate on learning that eventually will also reduce the learning achievement.

Speaking of learning achievement, when compared to the results of the assessment of learning process in school with the achievement of UN (National Examination), some of the students (51\%) of SMA, MA and SMK for all types of schools get the value under KKM (Minimum Completion Criteria) which students get for under average UN (70). Of the 9 test subjects, only 3 (about 33\%) for SMA and MA are above the KKM. So KKM schools for SMA and MA failed to predict the UN as an effective indicator of school success. For Vocational School, there are 5 out of 9 test subjects that is about $56 \%$ below average, so there is a significant tendency that KKM schools in SMK cannot predict the national exam score because of only one eye of the UN test in SMK coloring the respective study program. respectively, while the other test subject is the supporting test. With at least the eyes of the test in the UN then the variant that can predict the UN score becomes small. If found no significant relationship, it can not be explained scientifically. In general, KKM cannot be used as an indicator of the success of the UN. This is contrary to the concept of the school success (Scheerens, 2015).

When viewed from the number of students in one class in high school mostly more than 33 people and in the private about 23 to 33 people. As for MA and SMK, both public and private the number of students in a local ranged from 23 to 27 people. The results of observations in the field of favorite schools will have many students. This indicates not yet the maximum set by the head of the service.

Furthermore, it is seen that the indicators are: mastering the material, mastering the science of education, mastering the guiding way of the students, mastering the learning method of conducting an evaluation, learning planning, personality integrity, social competence, work ethic, school uniqueness, curriculum as a document, There are six indicators that the median is below average: mastering the material, mastering the science of education, mastering the way of guiding students, mastering the methods of learning, carry out an evaluation, learning planning. Judging from the opinion (Tyler, 2013), starting planning objectives, experiences, methods, and evaluation of learning have not been done, it means that all aspects of the Behavioristic curriculum have not been met.

A result of Problem Analysis of School of Inclusive Education Provider in Padang City based on teacher, student, school, community, and government problem is as follows: Judging from the number of schools of inclusive education providers there are only four schools for the academic year 2016/2017 ie SMKN 4,6,7, and 8 with total number 56 students spread in SMK Negeri 4 as many as 18 people, SMK Negeri 6 as many as 27 people, Negeri 7 as many as 8 people, SMK Negeri 8 as many as 3 people. The model of inclusive education held at SMK Negeri Padang is model inclusive moderate education. This moderate model is known as the mainstreaming model. The mainstreaming model of education is a model that combines education for children with special needs (Special School) with regular education. Specific needful learners are incorporated into regular classes only for some time. The philosophy remains inclusive education, but in practice, children with special needs are provided with various service alternatives according to their abilities and needs. Children with special needs may move from one service to another, such as (1) Full regular class form, Children with special needs to learn with other children (normal) throughout the day in regular classes using the same curriculum. (2) Form regular classes with clusters, Children with special needs to learn with other children (normal) in regular classes in special groups. (3) Form regular classes with pull outs, Children with special needs to learn with other children (normal) in regular classes but in certain times drawn from regular classes to the source room to learn with a special tutor. (4) Form regular classes with clusters and pull outs, Children with special needs to learn with other children (normal) in regular classes in special groups, and in certain times drawn from regular classes to the source room to learn together with special tutors. (5) Special classroom with multiple integrations, Children with special needs to study in special classes in regular schools, but in certain areas can learn with other children (normal) in the regular classroom. (6) Special full class form at regular school, Children with special needs in special classroom learning at a regular school.

Thus, inclusive education as in the above model does not require that all children with special needs be in regular classes at all times with all subjects (full inclusion). This is because some children with special needs can be in a special class or therapy room with a gradation of a fairly severe disorder. Even for children with special needs who have severe gradation disorders, it may be more time to be in a special class at a regular school (inclusion location). 
Figure 5. Percentage of Five Categories of Problems Related to ABK Students

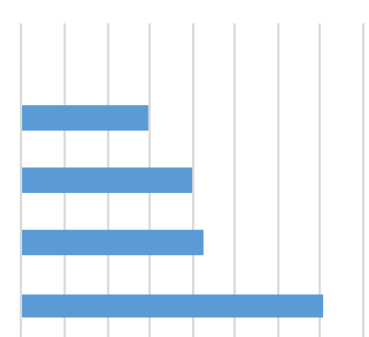

Figure 4. Percentage of Six Categories of Problems Related Parent ABK

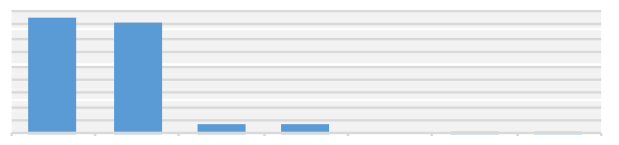

Figure 6. Percentage of Three Categories of Problems Related to School Management

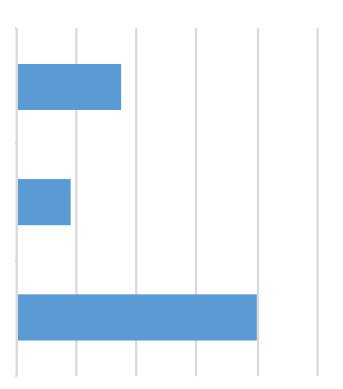

Then, for the level of the disorder is very heavy, and not possible in regular schools (regular school), can be channeled to special schools (SLB) or special place (hospital).

Problems that arise between one another when further examined will be related to each other, both from the problems of teachers, students, schools, community, and government. First, according to the data in Figure 3 regarding the problems of teachers, teachers complain that less competence in handling the crew. This is due to the lack of understanding of teachers about the crew and inclusion schools which then impact on the problems that arise next to the teacher difficulties in teaching and learning activities. This is also supported by the fact that there are some teachers who have inappropriate educational backgrounds and lack of Teachers Assistance Classes, thus increasing the burden of the teacher's workload both the administrative burden and the burden of teaching this also indirectly impact on how the teacher handles students in schools are not maximal and teachers are also faced with various ABK problems that vary and require different handling and the number of $\mathrm{ABK}$ that exceeds the quota in each class so that the impact on less smooth the process of KBM. The burden of teachers getting heavier when accepting the reality of the field that many of the parents of the crew is not concerned about the development of his child.

Based on Figure 4, b Many parents who then just let go completely on her child's development at school. This can also be due to the parent's understanding of the crew is still lacking. Another problem that arises is the tolerance or understanding of the parents of regular students to the needs of the crew is still less because many of the people who still look down on crews and inclusion schools so that people do not provide support related to the implementation of inclusive schools. This could be due to a lack of community knowledge related to inclusive education and $\mathrm{ABK}$.

Figure 5, teachers are also faced with various ABK problems that are different and require different handling while teachers have a heavy burden also for non-crew groups, thus impacting less smooth the process of KBM. This is also supported by the fact that there are some teachers who have inappropriate educational backgrounds and lack of Teachers Assistance Classes, thus increasing the burden of the teacher's workload both the administrative burden and the burden of teaching this also indirectly impact on how the teacher handles students in school is not maximal. Guidance models for learners with special needs, not focused on non-adaptive behavior or deviant behavior before they conduct activities of individual learning activities program.

Based on Figure 6, the burden of teachers and schools is increasingly heavy, where in general, schools themselves are not ready both in terms of administration and human resources in the implementation of education inclusion in the school, coupled with lack of support and cooperation from all parties, lack of infrastructure provided by the government related to the implementation of schools inclusion so that the implementation of inclusive schools cannot run optimally. 


\section{Figure 7. Percentage of Three Categories of Problems Related to the Government}

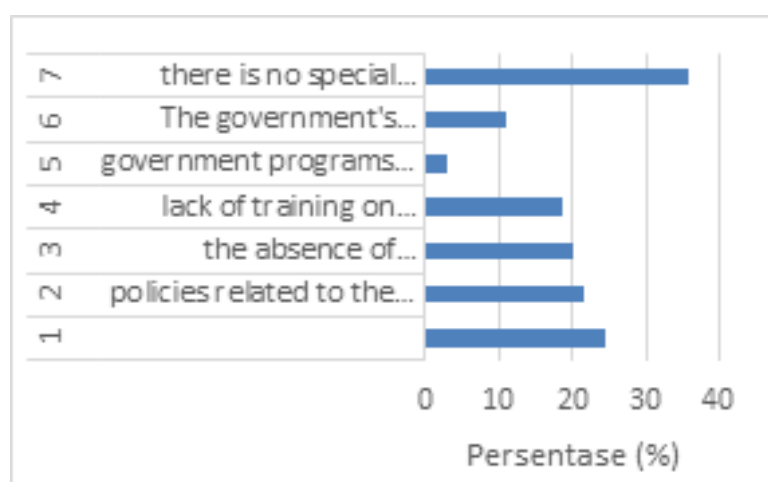

Figure 8. Percentage of Three Categories of Problems Related to the Community

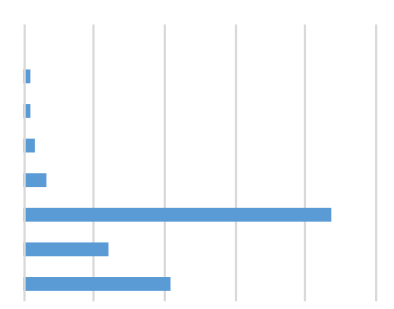

In Figure 7 Researchers see that the problem that arises actually because both schools, communities, and teachers have not fully understood and know how to handle the crew in particular. The results also show that schools and teachers also do not know how the implementation of inclusion schools in accordance with existing rules. This is because the Government is perceived as less able to disseminate policies related to the implementation of inclusive schools or the inclusive school policy itself is unclear and the lack of training conducted by the Government can improve teacher competence. The teacher considers that the attention and concern of the government towards the inclusion school is not good in terms of human resource welfare or related to human resource competence.

Figure 8 shows that many of the problems that arise concerning the implementation of inclusive schools in the case of teachers, students, parents, schools, communities, government, lack of facilities and infrastructure, and the lack of cooperation from various parties have an impact on the inclusion of existing schools.

\section{CONCLUSION}

Problems that arise between one another when further examined will be related to each other, both from the problems of teachers, students, schools, communities, and government. Firstly, on teacher issues, teachers complain that there is less competence in handling ABK. This is due to the lack of understanding of teachers about the crew and inclusion schools which then impact on the problems that arise next to the teacher difficulties in teaching and learning activities. Secondly, the problem on tolerance or understanding parents of regular students to the needs of the crew is still less because of a lot of people who still despise ABK and inclusive schools so that people are not giving support regarding the implementation of inclusive schools. This could be due to the lack of public knowledge related to inclusive education and ABK. Thirdly, the problems arising in respect of the implementation of inclusive schools in terms of teachers, students, parents, schools, communities, government, infrastructure is lacking, and the lack of cooperation from various parties that have an impact maximal implementation of inclusive schools that exist. Fourthly, the problem related to the school community, such as teachers, classroom assistant teacher, parents, students, school administrative team, and the school community to maximize the performance of teachers.

It is hoped that in the future other researchers and the government can focus on solving problems related to the teacher, such as increased understanding and competence of teachers because teachers are the spearhead in the implementation of education. A teacher is an important actor in the process of school reform. If the teacher understands and able to implement inclusive education in schools well, teachers can distribute knowledge to the public through either parent guardian or parent of the parent of the Non-ABK ABK. Governments have a responsibility for professional development / enhancement of teacher competence, although sometimes the system responsibilities were partly handed over to the organization of the school, because the school also has a role to make changes in the school, especially the principal, but not only focus on the teacher or employees and - people involved in the implementation of the school but also the need to increase social awareness of society to the school inclusion. The school is actually also can develop the school improvement through teachers and the parties involved. Schools also have a duty to increase public awareness with the support of various government its special parties. 


\section{REFFERENCE}

Carrington, S., \& Robinson, R. (2004) A case study of inclusive school development: a journey of learning. The International Journal of Inclusive Education, 8(2), 141-153.

Festiyed. (2015). Integrate Approach To Scientific Inquiry Model Assessment And Authentic.

Giangreco, M. F. (2013). Teacher assistant supports in inclusive schools: Research, practices and alternatives. Australasian journal of special education, 37(2), 93-106.

Mikail, B. (2012) School inclusion is not ready Accommodating ABK. http: // Education. kompas. com.
Scheerens, J. (2015). School effectiveness research. In International encyclopedia of social and behavioral sciences, 2nd edition. Elsevier.

Stainback, S. E., \& Stainback, W. E. (1992). Curriculum considerations in inclusive classrooms: Facilitating learning for all students. Paul H. Brookes Publishing.

Tarnoto, N. (2016). Problem-Problems Faced Education Provider School Inclusion On The Level Sd. Humanitas (Journal of Psychology Indonesia), 13 (1), 50-61.

Tyler, R. W. (2013). Basic principles of curriculum and instruction. In Curriculum Studies Reader E2 (pp. 60-68). Routledge. 